\title{
The Spontaneously Diabetic Wistar Rat (the "BB" Rat)
}

\author{
Studies Prior to and during Development of the Overt Syndrome
}

A. F. Nakhooda ${ }^{1}$, A. A. Like $^{2}$, C.I. Chappel ${ }^{3}$, C.-N. Wei ${ }^{1}$, and E. B. Marliss ${ }^{1}$

${ }^{1}$ Department of Medicine, University of Toronto, Toronto, Ontario, ${ }^{2}$ Department of Pathology, University of Massachusetts Medical Center, Worcester, Massachusetts, USA, and ${ }^{3}$ Bio Breeding Laboratories, Ottawa, Ontario, Canada

Summary. A longitudinal study of 51 weanlings from 5 litters of "BB" Wistar rats was undertaken to characterize the time course of the spontaneous diabetic syndrome. Nine rats developed overt diabetes. An abnormal glucose tolerance preceded the onset of the syndrome in 6 of these 9 rats. No other "clinical" or metabolic variable measured was predictive of the development of this syndrome. In these rats, the onset was remarkably abrupt, followed by rapid clinical deterioration with marked hyperglycaemia, glycosuria, ketonaemia and hypoinsulinaemia attained within 2 to 8 days. Pronounced insulitis was present in the early stages of the syndrome, resulting in complete B-cell destruction at the time of sacrifice at 7 to 40 days. Among the 42 littermates, 9 revealed sequential abnormalities in oral glucose tolerance tests performed at weekly intervals (to age 90-120 d) though remaining aglycosuric and maintaining normal fasting plasma glucose levels. In 7 of these rats, a milder form of the same islet inflammatory lesion seen in the overtly diabetic animals was present. Thus the new features identified are: 1) a time course of evolution from normoglycaemia to overt diabetes telescoped into a period of days, and 2) a "chemical" stage or form with an insulitis similar to that found in the early stages of overt diabetes.

Key words: Animal model, spontaneous diabetes, juvenile diabetes, plasma glucose, insulin, glucagon, ketones, oral glucose tolerance tests, chemical diabetes, insulitis, free fatty acids.

The spontaneously diabetic rat, now termed the "BB" rat, was first recognized in 1974 at the Bio Breeding Laboratories of Canada Ltd. (Ottawa) in an outbred colony of rats derived from a Wistar strain. Our initial studies of the diabetic syndrome [1] demonstrated it to occur in young non-obese rats and to be characterized by hyperglycaemia, glycosuria, hypoinsulinaemia, hyperglucagonaemia and ketosis. A unique feature of this syndrome was the presence of widespread pancreatic insulitis during active B-cell destruction.

The present report describes a more detailed characterization of the diabetic syndrome in the "BB" rat, by a longitudinal study of litters from weaning onwards. The major emphasis of this study was twofold: 1) to attempt to characterize the period prior to onset of overt diabetes, and to seek indices of impending development of the syndrome; and 2) to follow the early course of development of the overt disease from the first onset of glycosuria, for detailed characterization of the rate of progression once the syndrome has appeared. Because of the extensive B-cell destruction observed soon after onset of overt diabetes [1], studies concerning aetiology require that earlier stages of this process be identified.

\section{Materials and Methods}

\section{A. Animals and Experimental Procedures}

Fifty-one rats ( 27 males and 24 females) representing 5 whole litters were obtained from Bio Breeding Laboratories of Canada Ltd. (Ottawa, Ontario), aged 31 to 48 days at or shortly after weaning. The parents, in each instance, were an insulin-treated diabetic male and a non-diabetic female, which had produced diabetic offspring in 3-6 previous litters. The results of all studies were compared with those of age and sex-matched controls obtained from the same strain of Wistar rats, but from breeding pairs 
Table 1. Characteristics of the overtly diabetic rats

\begin{tabular}{|c|c|c|c|c|c|c|}
\hline $\begin{array}{l}\text { Litter } \\
\text { no. }\end{array}$ & $\begin{array}{l}\text { Diabetic } \\
\text { rat } \\
\text { no. }\end{array}$ & $\begin{array}{l}\text { Total in } \\
\text { litter }\end{array}$ & $\begin{array}{l}\% \\
\text { Incidence } \\
\text { of diabetes }\end{array}$ & Sex & $\begin{array}{l}\text { Age at } \\
\text { beginning } \\
\text { of study } \\
\text { (d) }\end{array}$ & $\begin{array}{l}\text { Age at } \\
\text { onset } \\
\text { (d) }\end{array}$ \\
\hline 1 & $\begin{array}{l}1 \\
2\end{array}$ & 12 & 17 & $\begin{array}{l}F \\
F\end{array}$ & $\begin{array}{l}48 \\
48\end{array}$ & $\begin{array}{l}56 \\
56\end{array}$ \\
\hline 2 & 3 & 11 & 9 & $\mathrm{~F}$ & 33 & 40 \\
\hline 3 & $\begin{array}{l}4 \\
5 \\
6\end{array}$ & 6 & 50 & $\begin{array}{l}\mathrm{F} \\
\mathrm{M} \\
\mathrm{F}\end{array}$ & $\begin{array}{l}31 \\
31 \\
31\end{array}$ & $\begin{array}{l}73 \\
83 \\
75\end{array}$ \\
\hline 4 & 7 & 10 & 10 & $\mathbf{M}$ & 45 & 85 \\
\hline 5 & $\begin{array}{l}8 \\
9\end{array}$ & 12 & 15 & $\begin{array}{l}\mathrm{M} \\
\mathrm{M}\end{array}$ & $\begin{array}{l}38 \\
38\end{array}$ & $\begin{array}{l}62 \\
87\end{array}$ \\
\hline
\end{tabular}

that had never produced diabetic offspring in a minimum of five sequential litters. Control animals were bred apart from the colony of rats which produced diabetics, and neither glycosuria nor hyperglycaemia was ever observed. The rats were housed in individual metabolic cages and fed powdered Purina lab chow (Ralston-Purina Co. of Canada Ltd., Woodstock, Ontario) ad libitum. Temperature, humidity, lighting, and air-conditioning were all controlled. Sequential daily food and water intake, urine volume, and body weight were recorded and the state of activity and hydration observed. Urine was collected in containers with $4 \mathrm{ml} 100 \mathrm{~g} / 1$ trichloracetic acid.

Blood from each animal was sampled twice weekly, once in a $6 \mathrm{~h}$ fasted state, and once after overnight fasting (about $18 \mathrm{~h}$ ). For the former, food was removed at $0900 \mathrm{~h}$ and blood sampled at $1500 \mathrm{~h}$. The frequency of sampling was increased in animals once fasting hyperglycaemia supervened. Sampling was from the orbital sinus under light ether anaesthesia. Volumes of $0.6-1.0 \mathrm{ml}$ of heparinized blood were obtained: an aliquot of whole blood was deproteinized with twice its volume of ice-cold $10 \mathrm{~g} / 100 \mathrm{ml}$ perchloric acid (PCA); the haematocrit was determined on a second aliquot. The remainder of the blood and the PCA sample were immediately centrifuged at $4^{\circ} \mathrm{C}$ and the PCA supernatant and plasma frozen at $-20^{\circ} \mathrm{C}$ until analysis. Prior to freezing, a volume of Trasylol $(10,000 \mathrm{KIU} / \mathrm{ml}$, from FBA Pharmaceuticals, Pointe Claire, Quebec) equal to one-tenth of the plasma was added. Oral glucose tolerance tests (GTT $0.25 \mathrm{~g} / 100 \mathrm{~g}$ body wt) were performed on the morning following the overnight fast, by gavage, at weekly intervals until fasting hyperglycaemia and glycosuria appeared, or until sacrifice. Blood samples were taken at 0,60 and 120 min after the glucose load.
The rats were studied to age $120 \mathrm{~d}$ for litters $1-4$, and $90 \mathrm{~d}$ for litter 5. Those which developed diabetes were followed untreated until their condition dictated sacrifice. In a few instances (especially in litter 5), animals were sacrificed at the time of one or more abnormal glucose tolerance tests, in the absence of fasting hyperglycaemia and glycosuria.

At sacrifice, again under light ether anaesthesia, heparinized blood was obtained by syringe from the aortic bifurcation. The pancreas was quickly removed and fixed in Bouin's solution. For lightmicroscopic examination, paraffin-embedded sections were stained with haematoxylin and eosin and with aldehyde fuchsin.

\section{B. Analyses}

Plasma and urine glucose were analyzed by the glucose oxidase technique of the Beckman Glucose Analyzer (Beckman Instruments, Inc., Palo Alto, Calif.). Blood 3-hydroxybutyrate, acetoacetate, lactate, and pyruvate were assayed on PCA supernatants by enzymic microfluorimetric methods [4]. Dole extracts of plasma were assayed for free fatty acids (FFA) by a radiochemical microtechnique [5] and unextracted plasma assayed for immunoreactive insulin (IRI) and immunoreactive glucagon [6] (IRG) by single-antibody charcoal-separation techniques [7]. Values were corrected for dilution by Trasylol. Anti-insulin antibody was obtained from Dr. P. H. Wright, Indianapolis, Ind., and purified rat insulin standard and ${ }^{125}$ I insulin from the Novo Research Institute, Copenhagen, Denmark (courtesy of L. G. Heding). Purified pork glucagon standard and ${ }^{125}$ I glucagon were also from the Novo Research Institute, and the relatively specific antipancreatic glucagon antibody $30 \mathrm{~K}$ was obtained from Dr. R. H. Unger, Dallas, Texas.

\section{Results}

\section{A. "Clinical" and Metabolic Studies}

\section{Overtly Diabetic Rats}

Onset of overt diabetes was defined as the day on which glycosuria was first observed. In the present series, transient glycosuria did not occur. When present, glycosuria was always associated with hyperglycaemia. Of the 51 rats followed, 9 became overtly diabetic (Table 1): 5 were females, 4 were males; age at onset varied from shortly after weaning (40 days, allowing only a short period for followup) to 
87 days. The sizes of litters varied from 6 to 13 pups, and the incidence between litters varied from 9-50\%.

a) "Clinical" Features: The body weights of the females (rats 1, 2, 3, 4 and 6) before onset were similar to those of their female littermates as well as to the body weights of age-matched controls previously published [1]. In contrast, the weights of the males (rats 5,7 and 8) were consistently lower than those of the controls, although their rates of growth were similar. Rats 1-8 continued to gain weight until 1-2 days before onset. Rat 9, a male, remained at a constant weight for 20 days prior to onset. After onset of diabetes all showed prompt decrease in weight, the rate of fall relating to the severity of the syndrome.

Twenty-four hour urine volumes and quantitative glycosuria are illustrated in Figure 1. Before onset the urine volumes were within the normal range, and were generally unchanged at first detection of glycosuria. Within 2 days, marked polyuria developed in association with a considerable increase in glycosuria. This rapid rise was followed by decrease in both variables as the clinical condition of the rats deteriorated. Daily food and water consumption (data not shown) showed no quantitative differences between these diabetic rats and nondiabetic littermates prior to onset.

b) Substrates and Hormones: The time courses of these variables are presented in Figures 2 and 3; only 6 hour fasting values are shown. Plasma glucose (Figure 2) concentrations were within the normal range prior to the onset of diabetes (142 $\pm 20 \mathrm{mg} / \mathrm{dl}$ for the age range spanned, $\bar{X} \pm \mathrm{SD}$ ). Sporadic samples were elevated ( 2 standard deviations above mean age-matched control values) in 2 rats, 10 and 11 days, and in 3 rats one day prior to onset. With onset of glycosuria, there was a sharp increase in glycaemia to levels of $300 \mathrm{mg} / \mathrm{dl}$ within one day, plateauing at levels of $500 \mathrm{mg} / \mathrm{dl}$ or greater within 6 days. This rapid evolution of hyperglycaemia was associated with a fall in plasma IRI levels below $0.5 \mathrm{ng} / \mathrm{ml}$ within 6 days (Figure 2). Many values were at or below $0.1 \mathrm{ng} / \mathrm{ml}$, the lower limit of detection of the assay. Rats 6,7 and 8 showed transient significant elevations of IRI (with reference to age matched controls) on days -11 or -17 , which were associated with normal plasma glucose levels. Plasma IRG showed little variation prior to onset of diabetes, with all values falling within the normal range $(250 \pm 70 \mathrm{pg} / \mathrm{ml})$. After onset, IRG levels rose, though not as rapidly as plasma glucose. At sacrifice hyperglucagonaemia

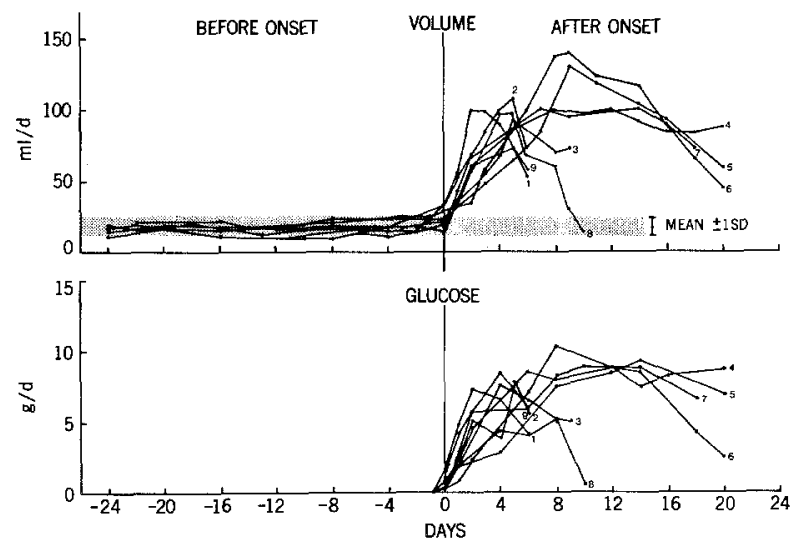

Fig. 1. $24 \mathrm{~h}$ urine volume and glucose in the diabetic rats before and after onset of diabetes. The bar on the right and corresponding shaded area show the mean \pm SD of values for normal control rats, spanning the age range of the diabetics
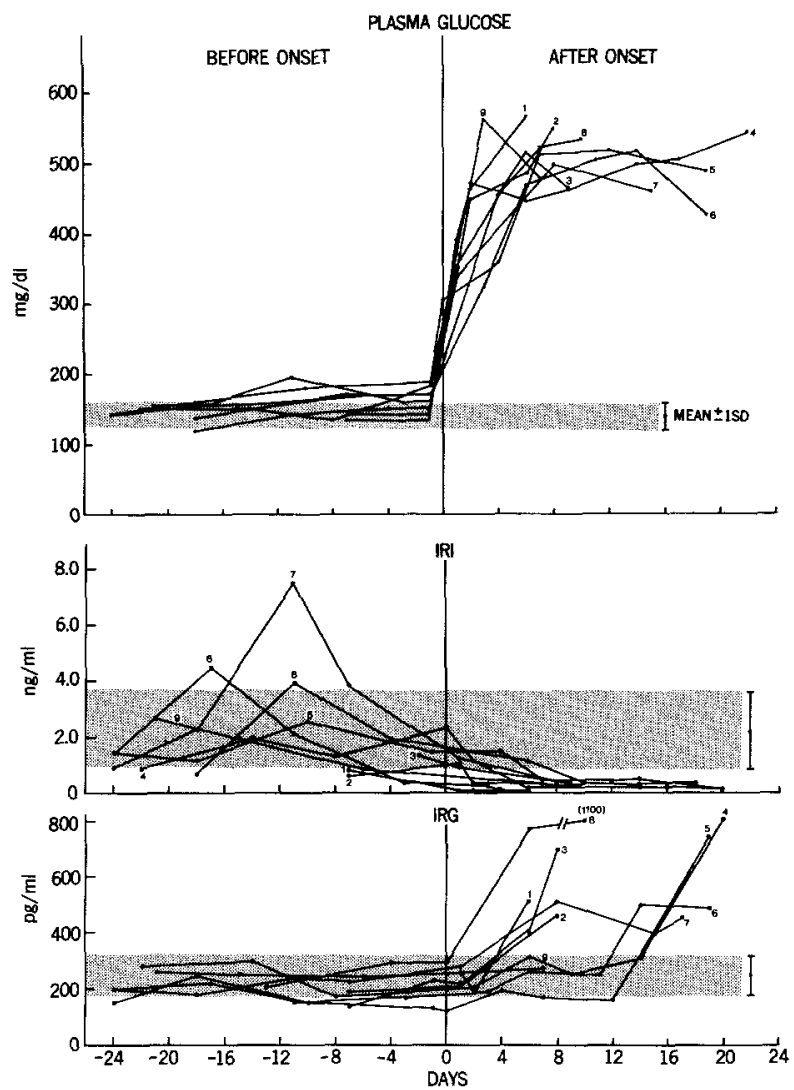

Fig. 2. Plasma glucose, insulin and glucagon in the diabetic rats before and after onset of diabetes. Mean \pm SD of control values encompassing the age range of the diabetic rats are shown as in Figure 1 

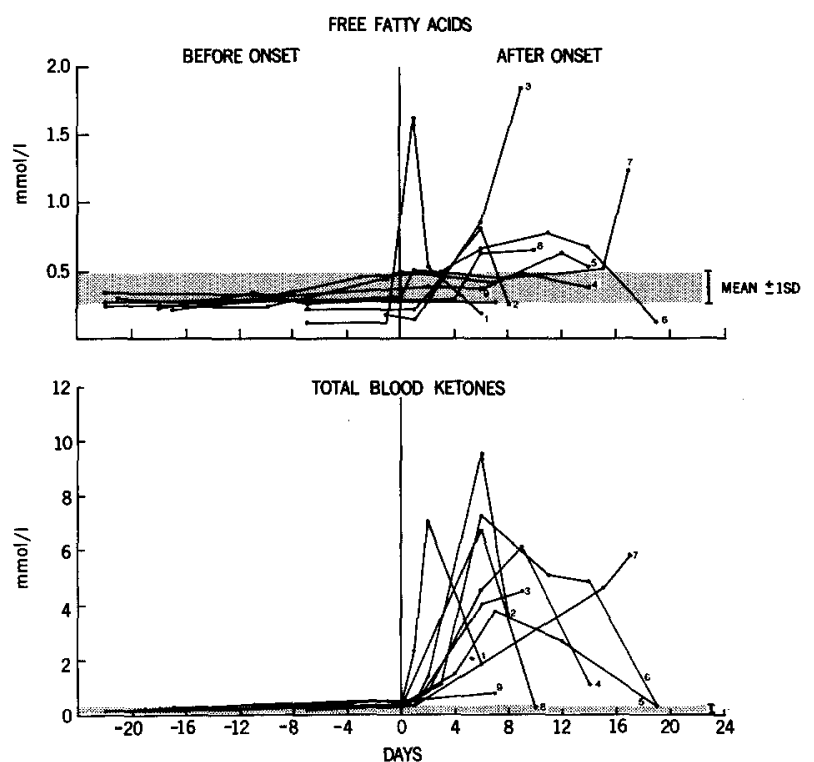

Fig.3. Plasma free fatty acids and total blood ketones (sum of 3-hydroxybutyrate and acetoacetate) in the diabetic rats before and after onset of diabetes. The mean \pm SD of control values are indicated by the shaded areas

Table 2. Oral glucose tolerance tests $(0.25 \mathrm{~g} / 100 \mathrm{~g}$ body wt) A. Control rats $(\bar{X} \pm S E M)$

\begin{tabular}{|c|c|c|c|c|c|c|c|}
\hline \multirow[t]{2}{*}{$\mathrm{n}$} & \multirow{2}{*}{$\begin{array}{l}\text { Age } \\
\text { (d) }\end{array}$} & \multicolumn{3}{|c|}{ Plasma glucose $(\mathrm{mg} / \mathrm{dl})$} & \multicolumn{3}{|c|}{ Plasma insulin $(\mathrm{ng} / \mathrm{ml})$} \\
\hline & & $0^{\prime}$ & $60^{\prime}$ & $120^{\prime}$ & $0^{\prime}$ & $60^{\prime}$ & $120^{\prime}$ \\
\hline 25 & 44 & $\begin{array}{r}104 \\
\pm \quad 3\end{array}$ & $\begin{array}{r}174 \\
\pm \quad 3\end{array}$ & $\begin{array}{r}160 \\
+\quad 3\end{array}$ & $\begin{array}{r}0.31 \\
\pm 0.03\end{array}$ & $\begin{array}{r}0.48 \\
\pm 0.04\end{array}$ & $\begin{array}{r}0.35 \\
\pm 0.03\end{array}$ \\
\hline 25 & 58 & $\begin{array}{r}117 \\
\pm \quad 3\end{array}$ & $\begin{array}{r}194 \\
\pm \quad 5\end{array}$ & $\begin{array}{r}173 \\
\pm \quad 4\end{array}$ & $\begin{array}{r}0.42 \\
\pm 0.04\end{array}$ & $\begin{array}{r}0.95 \\
\pm 0.10\end{array}$ & $\begin{array}{r}0.57 \\
\pm 0.06\end{array}$ \\
\hline 6 & 87 & $\begin{array}{r}122 \\
\pm \quad 5\end{array}$ & $\begin{array}{r}191 \\
\pm \quad 9\end{array}$ & $\begin{array}{r}168 \\
\pm \quad 12\end{array}$ & $\begin{array}{r}0.54 \\
\pm 0.11\end{array}$ & $\begin{array}{r}1.44 \\
\pm 0.40\end{array}$ & $\begin{array}{r}1.33 \\
\pm 0.42\end{array}$ \\
\hline
\end{tabular}

B. Overtly diabetic rats ${ }^{\mathrm{a}}$

\begin{tabular}{|c|c|c|c|c|c|c|c|c|c|}
\hline \multirow{2}{*}{$\begin{array}{l}\text { Rat } \\
\text { no. }\end{array}$} & \multirow{2}{*}{$\begin{array}{l}\text { Total } \\
\text { no. of } \\
\text { GTT's } \\
\text { performed }\end{array}$} & \multirow{2}{*}{$\begin{array}{l}\text { Days } \\
\text { prior } \\
\text { to } \\
\text { onset }\end{array}$} & \multirow{2}{*}{$\begin{array}{l}\text { Age } \\
\text { (d) }\end{array}$} & \multicolumn{3}{|c|}{$\begin{array}{l}\text { Plasma glucose } \\
\mathrm{mg} / \mathrm{dl}\end{array}$} & \multicolumn{3}{|c|}{$\begin{array}{l}\text { Plasma insulin } \\
\mathrm{ng} / \mathrm{ml}\end{array}$} \\
\hline & & & & $0^{\prime}$ & $60^{\prime}$ & $120^{\prime}$ & $0^{\prime}$ & $60^{\prime}$ & $120^{\prime}$ \\
\hline & 1 & 2 & 54 & 10 & 29 & $229^{b}$ & 0.20 & 1.76 & 0.74 \\
\hline 2 & 1 & 2 & 54 & 110 & $295^{b}$ & 200 & 0.20 & 1.43 & 1.06 \\
\hline 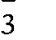 & 1 & 4 & 36 & 109 & 190 & 131 & 0.36 & 0.68 & 0.40 \\
\hline 4 & 5 & 12 & 61 & 101 & 171 & 180 & 0.52 & 0.74 & 0.86 \\
\hline 5 & 6 & 7 & 74 & 114 & $242^{b}$ & $224^{b}$ & 0.81 & $3.74^{b}$ & 1.45 \\
\hline 6 & 6 & 1 & 74 & 124 & $440^{\mathrm{b}}$ & $359^{\mathrm{b}}$ & 0.11 & 0.42 & 0.30 \\
\hline 7 & 5 & 4 & 82 & 98 & 16 & 151 & 0.44 & 1.32 & 1.72 \\
\hline 8 & 4 & 1 & 61 & 99 & 191 & $333^{b}$ & 0.25 & 0.44 & 0.50 \\
\hline 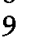 & 6 & 11 & 76 & 102 & $253^{\mathrm{b}}$ & $310^{b}$ & 0.28 & 0.81 & 0.81 \\
\hline
\end{tabular}

${ }^{a}$ Results of the last OGTT prior to onset

b Values greater than mean +2 SD of age-matched controls was present in 8 rats, with marked elevations in most.

Concurrent with the deterioration in glucose homoeostasis and the decline in IRI levels, were changes in circulating fat-derived energy substrates. Plasma free fatty acids and blood total ketone bodies (the sum of 3-hydroxybutyrate and acetoacetate) are shown in Figure 3. Before the onset of diabetes, FFA and ketone bodies were all within the normal range (FFA: $0.37 \pm 0.13 \mathrm{mmol} / \mathrm{l}$, ketone bodies $0.21 \pm 0.15 \mathrm{mmol} / \mathrm{l})$. At onset the FFA and ketone bodies both rose in most animals though by a variable degree. Of interest is the subsequent decline in both FFA and ketone body levels in 6 rats. The nadirs reached were within or below the normal control values in several instances. Blood lactate and pyruvate concentrations at each sampling showed no changes either prior to or after onset of diabetes (data not shown).

c) Oral Glucose Tolerance Tests: One to 7 sequential oral glucose tolerance tests, 28 in total, were performed. The normality of a response was determined by comparison with the responses of agematched, non-littermate controls. The responses in these control animals are shown in Table $2 \mathrm{~A}$. A progressive increase in the upper limit of glycaemia and a change in insulin response occurred with age. No difference was found between the responses of males and females. An abnormal value was defined as one which was greater than $2 \mathrm{SD}$ above the mean of the controls.

Table $2 \mathrm{~B}$ presents the results of the last test performed prior to onset of diabetes in each rat. An abnormal glycaemic response was obtained in 6 of the 9 rats. All fasting plasma glucose values were normal, but values greater than $250 \mathrm{mg} / \mathrm{dl}$ occurred at $60 \mathrm{and} /$ or $120 \mathrm{~min}$ in 5 of the 6 rats. The insulin response was within the normal range in all rats except number 5 . In this rat an excessive response was observed at $60 \mathrm{~min}$.

Analysis of the GTTs performed prior to the last one before onset of diabetes showed normal glycaemic responses in all rats, with the exception of rat 9 , on one occasion. The insulin responses, however, showed several abnormalities. Eight rats revealed a pattern of delayed hypersecretion in 1 or 2 prior tests. This pattern is illustrated for rat 8 in Figure 4 . Of the 4 tests, the first 3 were normal with respect to glycaemic response. However, the IRI response which was normal in the first GTT showed a marked increase at $120 \mathrm{~min}$ in the second, and (concurrent with decrease in glucose tolerance) in the third test there was a late IRI rise, but to a lesser degree. A further decrease in IRI response in the 

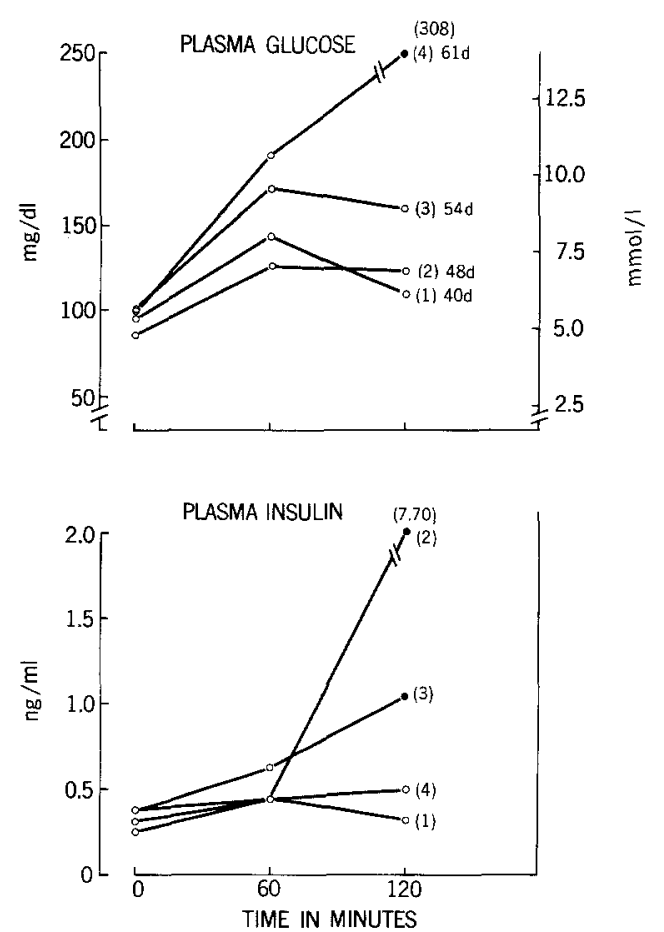

Fig. 4. Results of 4 sequential oral glucose tolerance tests $(0.25 \mathrm{~g} / 100 \mathrm{~g}$ body wt) in rat 8 . The age of the rat at the time of each test is indicated. The rat became diabetic at age 62 days. Closed circles represent values greater than 2 SD above the mean of age-matched controls. See text for details

final test was accompanied by an abnormal plasma glucose at $120 \mathrm{~min}$, one day prior to onset of diabetes.

\section{Littermates}

Among the 42 littermates followed, none developed fasting hyperglycaemia or glycosuria. The 32 rats of litters 1-4 showed the weight gain, food and water intake, and urine volume of normal control rats. In the fifth litter, the growth rates of 10 animals ( 5 male, 5 female) were retarded, and at sacrifice their body weights were significantly less $(p<0.05)$ than those of unrelated controls. Weights of females were $179 \pm 11 \mathrm{~g}$ (controls at 90 days $=243 \pm 9 \mathrm{~g}$, $\mathrm{n}=12$ ) and of males were $174 \pm 11 \mathrm{~g}$ (controls $=350 \pm 7 \mathrm{~g}, \mathrm{n}=12$ ). Food intake was correspondingly less. The substrate and hormone levels measured, however, were not different from those of the other 4 litters, and none differed from the appropriately age-matched controls previously reported [1].

Five to 9 weekly sequential oral glucose tolerance tests were performed on these 42 animals, from the outset of the study to the time of sacrifice.
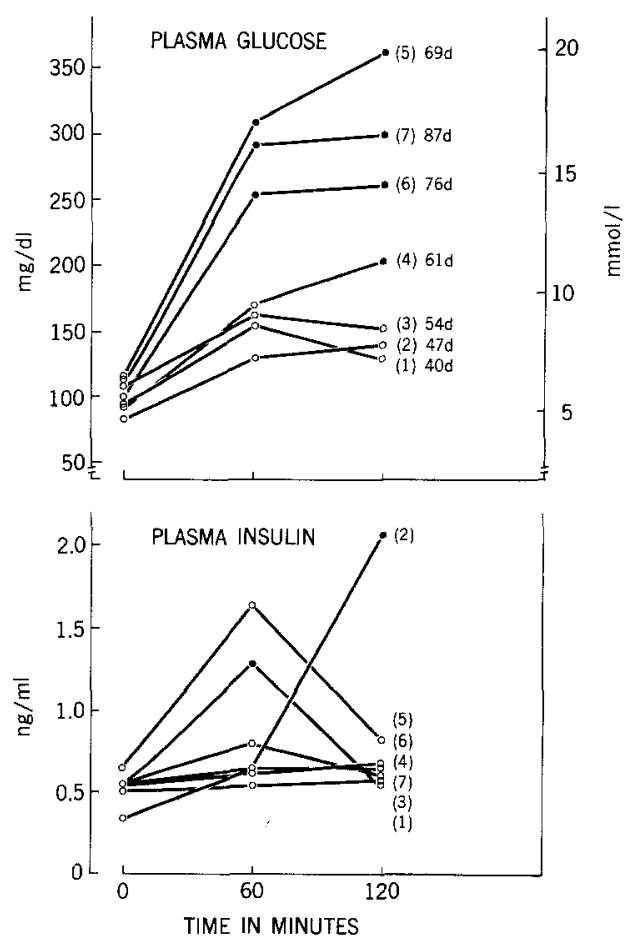

Fig. 5. Results of sequential oral glucose tolerance tests $(0.25 \mathrm{~g} / 100 \mathrm{~g}$ body wt $)$ in a rat from litter 5 which did not become overtly diabetic. The age of the rat at the time of each test is indicated. Closed circles represent values that are greater than $2 \mathrm{SD}$ above the mean of age-matched controls. See text for details

In all, a total of 283 tests were performed. A summary of the occurrence of normal and abnormal glucose and insulin responses is shown in Table 3. Twenty-three rats $(55 \%)$ never showed abnormal plasma glucose and $9(21 \%)$ never showed abnormal insulin responses. Ten rats showed random glycaemic abnormalities, representing $6 \%$ of the total number of tests performed. Twenty-eight rats showed random abnormalities of insulin response (18\% of the total tests performed). These abnormalities in most instances were at single time points, i. e., either 60 or $120 \mathrm{~min}$. Furthermore, on most occasions an abnormal glycaemia was not associated with an abnormal insulin response. In only 6 tests (in different rats) were concurrent abnormalities in both glucose and insulin response observed.

Of greater interest were the abnormal glycaemic responses observed on 2 or more consecutive occasions in 9 rats (Table 3 ). The glucose and insulin patterns during sequential GTT's in one animal which typifies this group are shown in Figure 5. This rat (from litter 5) had 7 tests performed at weekly intervals. All started from normal fasting plasma glucose levels. The first 3 tests were normal. The fourth showed a single abnormality at $120 \mathrm{~min}$, and 
Table 3. Plasma glucose and insulin results during sequential OGTT's in littermates

\begin{tabular}{llc}
\hline Type and frequency of response & \multicolumn{2}{l}{ No. of rats } \\
\cline { 3 - 3 } & Glucose & Insulin \\
\hline Normal in all tests & 23 & 9 \\
$\begin{array}{l}\text { One abnormal test } \\
\text { Two abnormal tests }\end{array}$ & 8 & 19 \\
$\quad$ Random & & \\
$\quad$ Consecutive & 1 & 8 \\
Three abnormal tests & 2 & 5 \\
$\quad$ Random & & \\
$\quad$ Consecutive & 1 & 1 \\
Four abnormal tests & 4 & - \\
$\quad$ Random & & \\
$\quad$ Consecutive & - & - \\
\hline
\end{tabular}

Table 4. Correlation of GTT results with pancreatic morphology in littermates

\begin{tabular}{lcllllll}
\hline & & \multicolumn{3}{l}{$\begin{array}{l}\text { No. of abnormal glycemic } \\
\text { responses }\end{array}$} \\
\cline { 3 - 8 } Morphology & No. of rats & None & 1 & 2 & 3 & 4 \\
\hline Normal & 35 & 23 & 7 & $2^{\text {a }}$ & $1^{\mathrm{b}}$ & $2^{\mathrm{c}}$ \\
Abnormal & 7 & - & 1 & $1^{\mathrm{c}}$ & $4^{\mathrm{c}}$ & $\mathbf{1}^{\mathrm{c}}$
\end{tabular}

a In one rat, the abnormalities were consecutive, in the other, random

$b$ These abnormalities were random

c These abnormalities were consecutive

the remaining 3 tests were clearly abnormal. The IRI responses were abnormally elevated in the first 2 tests, when plasma glucose values were normal. These were followed by a trend towards a decrease into the normal range of response in the third and subsequent tests (except the fifth) as glucose intolerance developed. These IRI responses were clearly inappropriately low for these elevated blood glucose levels though sufficient reserve was present to maintain fasting normoglycaemia.

\section{B. Morphologic Studies}

The light microscopic observations were made on coded samples and correlated thereafter with the metabolic data on each animal.

\section{Overtly Diabetic Rats}

The 9 rats were sacrificed at differing times after onset of diabetes, with varying degrees of metabolic decompensation. In rats with severe decompensation, irrespective of time of sacrifice, an "end-stage" morphologic picture was present. This is illustrated for rat 7 in Figure $6 \mathrm{~A}$ at 17 days after onset. Islets were small, decreased in number and consisted almost entirely of non B-cells. This islet differs from one showing profound insulitis (Figure 6B) observed in rat 9 with a milder metabolic derangement, sacrificed 7 days after onset. It is characterized by B-cell destruction and marked infiltration by leucocytes (mainly mononuclear) in and around the islets.

\section{Littermates}

Thirty-five of these 42 rats (sacrificed at 90 or 120 days of study) had completely normal pancreatic morphology (Figure 6C). The other 7 exhibited significant morphologic changes. Mild degrees of insulitis, with B-cell destruction, were present (Figure 6D). The islet architecture was distorted by the presence of inflammatory cells permeating the interior and surrounding the periphery of the islets. This morphologic picture has also been observed in approximately $25 \%$ of another group of $32 \mathrm{ag}$ lycosuric littermates of overt diabetics, sacrificed without glucose tolerance testing (A. A. Like, unpublished data).

Since responses to oral glucose were the only variables that showed deviations from the normal controls in these littermates, the glycaemic responses during the sequential tests were compared with the morphologic findings (Table 4). Of the 35 rats that showed normal morphology, 30 had normal or only single sporadic anomalies of glycaemia. The other 5 showed abnormal responses which occurred consecutively in 3 . On the other hand, all 7 rats that had abnormal morphology, also had one or more consecutive abnormal GTT's. The last abnormal response in this group occurred in one rat, on the day of sacrifice, and in the other 6 animals, 7 days before sacrifice. In the 5 rats with normal morphology, the time lapse between last abnormal GTT and sacrifice was $7-20$ days.

\section{Discussion}

We have previously studied diabetic "BB" rats with a view to characterizing the nature of the syndrome [1]. Those animals were studied beginning 3-7 days after onset of glycosuria, because the monitoring programme of the breeding facility consisted of 2 tests for glycosuria weekly. They were shown to have a spectrum of severity of diabetes related to the extent of islet cell destruction from "stable", with hyperglycaemia but without ketosis, to increasing intensity of ketosis. In the present study more detailed monitoring of the animals just prior to and after the onset of glycosuria was possible. 


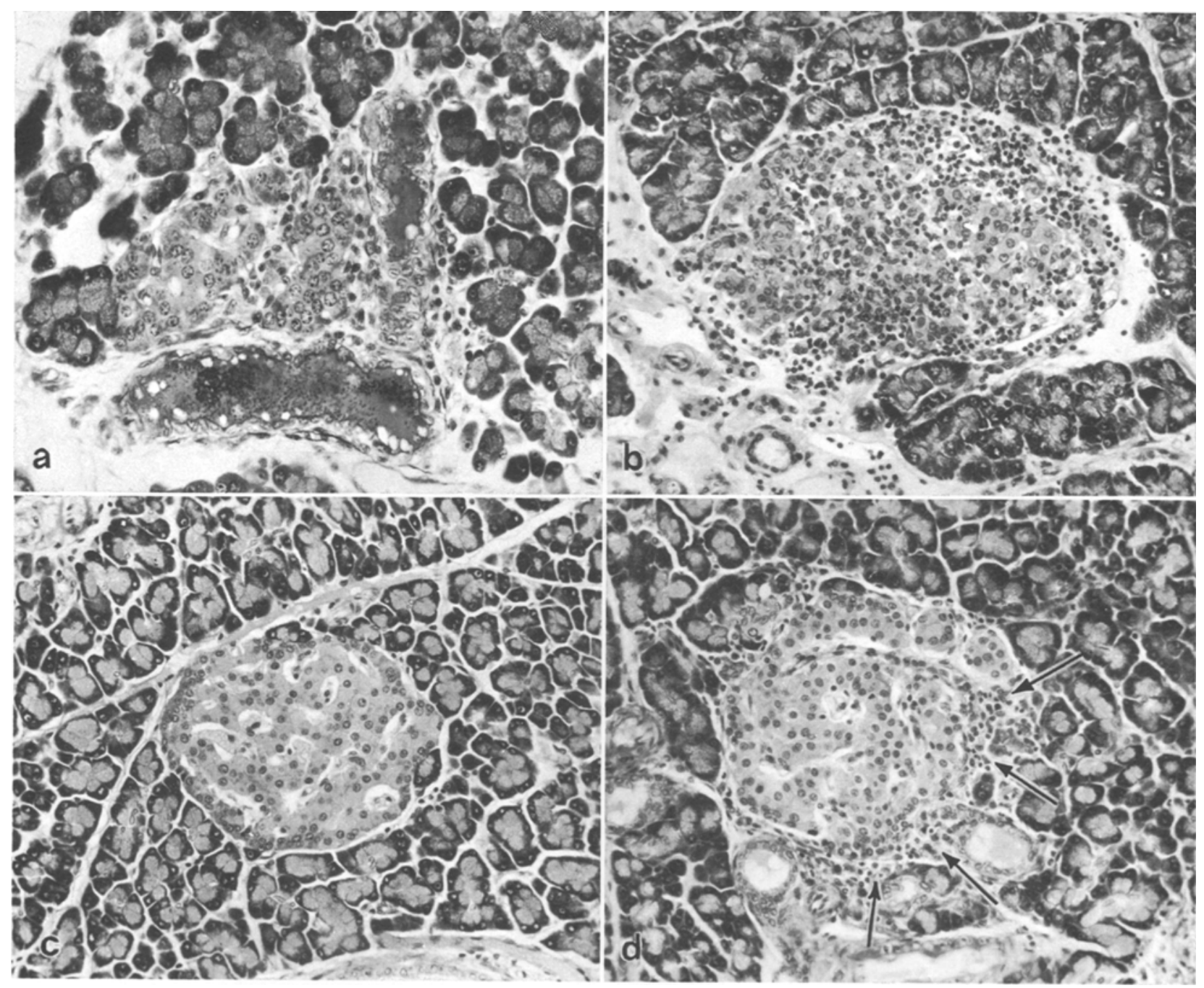

Fig. 6. a Small end stage islet of animal with pronounced hyperglycaemia and ketoacidosis. The reduction in size is a manifestation of almost complete B-cell destruction. Inflammatory cells are reduced in number. Aldehyde fuchsin $395 \mathrm{X}$. b Islet from an animal with an early or intermediate (clinical and morphologic) stage of the syndrome. Insulitis is pronounced with numerous infiltrating leucocytes (predominantly mononuclear) within and around the pancreatic islets. Haematoxylin and eosin $198 \mathrm{X}$. $\mathbf{c}$ Pancreatic islet of littermate with normal plasma glucose and insulin levels and normal glucose tolerance tests. This section reveals the well delineated islet and the surrounding acinar cells. Inflammatory cells are absent. Haematoxylin and eosin $198 \mathrm{X}$. d Pancreatic islet of a littermate with consecutive abnormal glucose tolerance tests, but with normal fasting plasma glucose, and insulin levels. Moderate numbers of inflammatory cells (arrows) surround and infiltrate the islet periphery with resulting architectural disarray of adjacent endocrine and exocrine tissue components. This early inflammatory lesion may progress to the fully expressed insulitis illustrated in Figure 6 A. Haematoxylin and eosin $198 \mathrm{X}$

This has demonstrated that the onset of the overt syndrome is extremely rapid, occurring over intervals of hours to a few days. Measurements of body weight, food and water intake on a daily basis gave no clear warning of impending diabetes, even during the week before, when compared either with normoglycaemic littermates or unrelated controls. Indeed, the only possible indicator of susceptibility based on these variables was the lower body weight in 3 of the 4 male rats. The sudden onset of diabetes was followed by rapid "clinical" deterioration. Marked hyperglycaemia occurred within a day of onset, and was associated with decreased plasma IRI and elevated FFA and ketone body levels. The rise in plasma IRG was slower, more variable in magnitude, and maximal at sacrifice. Of interest is the later decrease of FFA and ketone body levels during severe diabetic decompensation. This suggests that body lipid stores were depleted, a finding supported by the lack of visible adipose tissue at postmortem. This "end-stage" metabolic state in the diabetic "BB" rats was previously shown to be associated with a massive decrease in $\mathrm{B}$-cell population and extractable IRI of less than $1 \%$ of control values. The 
present study has confirmed the presence of this end-stage morphologic picture, with the few, remaining small islets containing virtually only non B-cells.

In the rats which developed overt diabetes the rapidity of the downhill course is further emphasized by the GTT results. In only 6 of the 9 was an abnormal GTT result obtained, the other 3 showing normal results as close as 4 days before onset. The longest period between an abnormal GTT and onset was 11 days. It is noteworthy that the abnormal glycaemic response was associated with hyperinsulinaemia in only one rat and inappropriately normal IRI in others. The insulin assay system used was not capable of distinguishing the nature of the circulating insulin immunoreactivity. It is possible that an altered proportion of IRI was present as proinsulin [8], accounting for the glucose intolerance. Alternatively, either altered molecules of "small" insulin might have been secreted, or the presence of periods of unrecognized hyperinsulinaemia may have served to decrease insulin receptors so as to result in decreased biological effectiveness of the insulin present [9].

The frequency of abnormal values during GTTs, as sporadic events in the littermates with normal fasting glycaemia, IRI and pancreatic morphology, could have a number of explanations. It is possibly an artefact related to the form of anaesthesia used for blood sampling. Alternatively, it is conceivable that transient and/or remitting forms of the syndrome exist. Such a possibility is further supported by the observation that in two littermates with 4 sequential abnormal GTTs, the pancreatic histology was normal. However, this latter finding might also be explained by the fact that abnormal B-cell function need not be associated with light microscopic changes, or that subtle decreases in B-cell number might have been present, but only demonstrable by detailed morphometric analysis.

The more interesting observation in this context was that when sequential abnormal glycaemic responses were documented in 9 littermates, significant insulitis was observed in 7 . These changes were never seen in littermates which showed only normal GTTs. These findings could thus represent a variant of the syndrome with insufficient B-cell destruction to manifest frank diabetes, or a stage in the evolution to the overt syndrome. In the latter case, it would suggest that a period as long as 4 weeks of "chemical" diabetes might exist in some animals.

In summary, the diabetic syndrome described exists in at least two forms, which could represent different stages of the disease. The first form overt diabetes - has been characterized as to severity [1] and time course. The second form is "chemi- cal" diabetes - characterized by sequential abnormalities of the GTT, in the presence of normal fasting glycaemia, with significant insulitis present in the majority of such animals. The GTT has been shown to be a useful predictor of both the development of overt diabetes and of abnormal islet morphology. It is relatively specific in that no abnormal morphology was found in animals without either overt diabetes or sequential abnormalities.

In comparing the "BB" rat with other spontaneous diabetic syndromes in laboratory animals, the Chinese hamster is the only similar one, in being non-obese, and sometimes ketotic when hyperglycaemia occurs. Like the "BB" rat, the diabetic syndrome has an early onset, occurring in the majority of animals between one and 3 months and being earlier in the offspring of ketotic matings [10]. The severely ketotic rats show rapid deterioration in "clinical" state after onset and live untreated only 1-3 weeks. The ketonuric Chinese hamster, on the other hand, has been reported to survive from about 72 to 120 weeks [10]. Prediabetic Chinese hamsters, born of inbred ketonuric parents, have increased food consumption and growth rates prior to the onset of glycosuria [11, 12]. Others, however, from non-ketonuric diabetic parents of 2 different inbred sublines, do not display accelerated growth or hyperphagia during the prediabetic stage [10]. This latter pattern has been observed in the "BB" rats. Detailed monitoring of the various biochemical parameters as presented in this paper have not been reported for the prediabetic Chinese hamster. Chinese hamsters have been reported to show no correlation between glycosuria after an oral glucose load and the incidence and/or onset and/or severity of the subsequent diabetes [10]. The "BB" rats are amenable to much more detailed study by virture of size and ease of handling. The present study has served to identify the time-periods during development of the overt syndrome and during chemical diabetes most likely to yield useful future data on the nature of the B-cell dysfunction and pathology.

Acknowledgements. We gratefully acknowledge the excellent and enthusiastic technical assistance of Katarina Thumm, Thelma Peregrino-Solomon, and Hing-Luen Tang, and the assiduous secretarial services of Dalita Berejikian. The collaboration of Drs. James Chambers and Reginald Chappel and Mr. Martin Bueno at Bio Breeding Laboratories, Ottawa, are gratefully acknowledged, as is the consultation with Drs. Norman Kalant and Naomi Fitch, of the Lady Davis Research Institute of the Jewish General Hospital, Montreal, Quebec, and with Dr. Abner L. Notkins of the National Institutes of Health, Bethesda, Md.

This work was supported by grants from the Juvenile Diabetes Foundation and Juvenile Diabetes Research Foundation of Canada (EBM), from the Redpath Sugar Company, Montreal, Quebec (CIC), and from the National Institutes of Health (AM-19155) and the Juvenile Diabetes Foundation (AAL). 


\section{References}

1. Nakhooda, A. F., Like, A.A., Chappel, C. I., Murray, F.T., Marliss, E.B.: The spontaneously diabetic Wistar rat metabolic and morphologic studies. Diabetes 26, 100-112 (1977)

2. Herberg, L., Coleman, D.L.: Laboratory animals exhibiting obesity and diabetes syndromes. Metabolism 26, 59-99 (1977)

3. Like, A. A.: Spontaneous diabetes in experimental animals. In: B. W. Volk, K. F. Wellman (eds.): The Diabetic Pancreas. Oxford: Plenum Press (In press)

4. Girard, J.R., Cuendet, G.S., Marliss, E. B., Kervan, A., Rieutort, M., Assan, R.: Fuels, hormones, and liver metabolism at term and during the early postnatal period in the rat. J. Clin. Invest. 52, 3190-3200 (1973)

5. Ho, R. J.: Radiochemical assay of long-chain fatty acids using ${ }^{63} \mathrm{Ni}$ as tracer. Anal. Biochem. 36, 105-113 (1970)

6. Faloona, G.R., Unger, R.H.: Glucagon. In: B.M. Jaffe, H.R. Behramn (eds.): Methods of Hormone Radioimmunoassay. Chapter 18, pp. 317-330. New York: Academic Press 1972

7. Herbert, V., Law, K.S., Gottlieb, C.W., Bleicher, S.J.: Coated charcoal immunoassay of insulin. J. Clin. Endocrinol. Metab. 39, 1375-1385 (1965)

8. Rubenstein, A.H., Horwitz, D.L., Steiner, D. F.: Proinsulin and Insulin Biosynthesis: Diabetes - Its Physiological and
Biochemical Basis, p. 1. Lancaster, U.K.: MTP Press Ltd. 1975

9. Kahn, C. R., Roth, J.: Insulin receptors in disease states. In: Hormone-Receptor Interaction: Molecular Aspects. Vol. 9, p. 1. New York: Marcel Dekker Inc. 1976

10. Gerritsen, G. C., Johnson, M. A., Soret, M. G., Schultz, J. R.: Epidemiology of Chinese hamsters and preliminary evidence for genetic heterogeneity of diabetes. Diabetologia 10, 581-588 (1974)

11. Gerritsen, G.C., Blanks, M.C.: Preliminary studies on food and water consumption of prediabetic Chinese hamsters. Diabetologia 6, 177-179 (1970)

12. Gerritsen, G.C., Blanks, M.S., Miller, R.L., Dulin, W.E.: Effect of diet limitation on the development of diabetes in prediabetic Chinese hamsters. Diabetologia 10, 559-565 (1974)

Received: July 1, 1977,

and in revised form: November 1, 1977

Dr. E. B. Marliss

Room 5242

Clinical Science Division

Medical Sciences Building

University of Toronto

Toronto, Ontario, M5S 1A8

Canada 